\title{
14. THE OPERAS OF PASCAL BENTOIU: THEMES, COLLECTIVE CHARACTER, ARS CHORALIS
}

\author{
Consuela Radu-T,aga ${ }^{126}$
}

\begin{abstract}
Pascal Bentoiu dedicated to the lyrical stage three opuses: the comedy The Love Doctor, the radio opera The Sacrifice of Iphigenia and the tragedy Hamlet. The female choir from The Sacrifice of Iphigenia and the choir from Hamlet use different ways of vocal expression, adapted to vibrations of the word: from recitative chanting or spoken chorus, to melodic articulations. The hegemony of the vocal parameter and the lyrical expression are counterpoised by the feverishness of the dramatic moments. Pascal Bentoiu proposes new elements in the structure of the opera genre, because in Hamlet the conceptual meanings of the overture are replaced by the choral prelude à cappella. The moments of choral treatment à cappella abound in his operas, these moments being full of emotion and expressing a deep sensitivity.
\end{abstract}

Key words: comedy, radio opera, tragedy, vibration of the word, choral ensemble

\section{Introduction}

Composer who put at stake the value of the music expressiveness, without eluding the virtues of modernism, Pascal Bentoiu dedicated to the lyrical stage three opuses: the comedy The Love Doctor, radio opera The Sacrifice of Iphigenia and the tragedy Hamlet. The first opera signed by the composer dates from 1964, bears the opus number 15 and it is a modern score in spirit, structure and language. The chosen themes aims at the entertainment, tending to correct the morals. Heading for the world of Molière's characters, Pascal Bentoiu opts for the use of musical quotation, technical process by which he falls in the direction of polystilism. In the satire the choral ensemble is not present, and the subject of the period reminds us of the acid spirit from The Stormy Night signed by Paul Constantinescu.

\section{The Sacrifice of Iphigenia}

Pascal Bentoiu composed The Sacrifice of Iphigenia (opus 17) at the command of the Romanian Radio Broadcasting Company. Written between the Symphony opus 16 and the opera Hamlet, the new experience of The Sacrifice of Iphigenia ranges between the spiritual verve of the comic opera The Love Doctor and the dramatic energy of the Shakespearean tragedy. Awarded with the Italian Broadcasting Prize, the work brings together the researches of the new sound effects with the dramatic nature of the radio opera's new style. "A very special personality, wearing the seal of an acute vibration sensitivity" $[3, \mathrm{p}$.

\footnotetext{
126 Lecturer PhD., “George Enescu” National University of Arts from Iaşi, Romania, email: taga_consuela@yahoo.com
} 
341], Pascal Bentoiu bravely attacked the path unused by the Romanian music until that time -1968 . The composer's statement supports the assertion: "the work is - as far as I know - the first of its kind written in Romania" [7, p. 320].

Supported also by the prize obtained, the work is an important achievement, a worldwide confirmation of the value of the Romanian school of musical composition, after the Enescu moment. Pascal Bentoiu appeals to a wide-ranging, perennial, generally human theme as reformer Gluck did, as well. The motif of conquering triumph by death is taken from Euripidean Iphigenia. To open the path of an army, Iphigenia sacrifices her life, and Agamemnon, her father, wins the war against Asia and Troy. The exaltation of the sublime death for a glorious cause was processed by Mircea Eliade in the play with the same title: Iphigenia.

The Romanian translator of Euridipes' work, Alexandru Mircea Pop, helped the composer to elaborate the libretto. They retained a small quantity of text, "the libretto being rather a literary support for the musical portrayal than a theatrical action itself, lacking the conflictual element exposed according to the dramaturgical evolution laws" [5, p. 288]. Following the path opened by Euripides, who saw the special expressive possibilities of music and singing, and gave an important role to the musical parts, where the choir, in a tone of almost exclusively lyrical commentary, confirms the action, the Romanian composer uses the choral ensemble made up of women's voices. The different ways of vocal expression are adapted to the vibration of the word: from recitative chanting or spoken chorus, to melodic articulations.

Bentoiu moves away from the dramatic motivations of the genre, so the score proposes only two main characters, accompanied by a group of instruments of the chamber type, composed of two sound sources: the big organ that ensures sound fluency, and the percussion partition for eight performers, that marks the beatings of the implacable destiny, the cry of horror and unleashes the brutal shock. The percussion-organ opposition presents the conflict between freedom and necessity, perenniality and exitus, obligation and hope, the desire to live and fatality, this being the fundamental conflict of the tragic genre. The single act is set up simply and soberly in 11 distinct sections, and the logic of musical-dramatic development uses leitmotifs that suggest ideas and characters.

The means of modern language equipped with electronic technique are investigated - magnetic tape - through which special effects such as increasing or decreasing intensities, echoes, mixing, timbre colouring are gained, and thus the poetic halo of drama is amplified. Iphigenia in its present form is an opera, that is a"musical action for voices and instruments, radiophonic, in the sense that the image is perfectly dispensed, its only dimensional field being the auditory one" [7, p. 320]. The spiritual thematic approach highlights the original vision of existence, the fineness of elaboration intertwined with the rigor of expression. The polymodal language gets maximum extensions through functional reporting 
or serial-dodecaphonic techniques (Lamento of Iphigenia) with a tendency to accumulate the chromatic scale. The hegemony of vocal parameter and lyrical expression are counterpoised by the feverishness of the dramatic moments. Musicality transpires, this being"the element that makes The Sacrifice of Iphigenia perfectly compatible with the perennial principles of the lyrical genre" [5, p. 289].

\section{Hamlet}

At full artistic maturity, in 1969, just a year after the radio opera The Sacrifice of Iphigenia, the composer Pascal Bentoiu headed back to the lyrical genre. Choosing a subject from Shakespeare's creation led to the realization of the only Romanian opera inspired by the Hamlet theme ${ }^{127}$. Dedicated to his professor Mihail Jora and awarded with the Guido Valcarenghi prize, the opera "Hamlet has become one of the most valuable scenic creations from the Romanian music" [5, p. 292], its rich world can be compared "to that of the great lyrical scores of the 20th century" [4, p. 41].

The strenuous work for the elaboration of the libretto coordinated the formation of not less than five versions that favor the musical deployment of drama. Preparing the libretto by himself, Pascal Bentoiu has resized the conflicting data from the Shakespearean drama, but maintained the essential configuration. The complex musical structure has given up some characters (such as Horatio, Prince of Norway, courtiers, ambassadors, servants, etc.), has modified some scenes, keeping the dramatic axis represented by Hamlet. The condensation of dramatic action has reduced the 19 scenes of the universal theater masterpiece (coupled in three acts) to just 10 (concentrated in two acts). From the experience of the previous lyrical works, the synthesis of the tradition of the opera from the meridional area was retained and the graduation of the architectural proportions related to the symphonic genre.

The coral ensemble is present in prelude, without determining a particular social category, then goes into the people's clothes in the second scene, then represents the group of seniors, ladies, guards, in a word the group of courtiers, in the tenth scene. Subscribing to the Shakespearean spirit, "the choir becomes a factor, an objective that, although it can wear various costumes, although it conveys a totally different kind of music, for instance in the third scene, compared to the sixth scene, remains unchanged in the stage function it has - to impress sound force for moments, and, moreover, here comes the contribution of the composer, to mark the pillars of support in the musical construction" $[6, p$. 127].

The conceptual meanings of the overture are replaced by the choral prelude à cappella, which "represents an introduction into the inner world of the main character, and an anticipation of the denouement" [6, p. 127]. A sound

${ }^{127}$ The subject was also treated by Ambroise Thomas. 
layer is formed in adagio, participating eight voices: first soprano, second soprano, first alto, second alto, first tenor, second tenor, bariton and bass. From A flat center sound abruptions take place between the first altos and the second, then between the first sopranos and the second, resulting thematic disposals of heterogeneous nature. Sonority flows in chromatic courses, without melodic highlights, with evolution between the extremes of pianississimo $\rightarrow$ fortissimo.

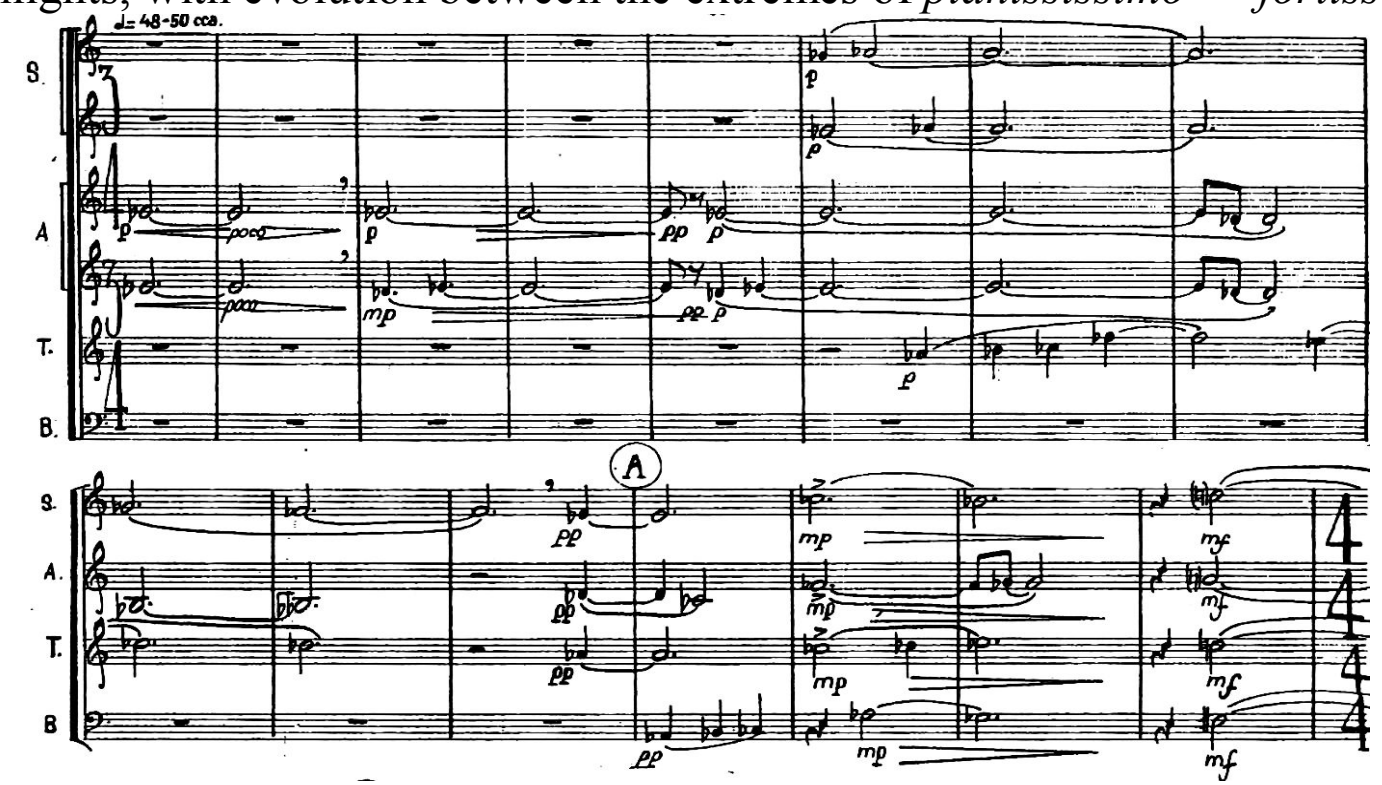

Figure no. 1. P. Bentoiu - Hamlet, preludium, p. 1, mm. 1- 15

Increases and decreases in intensity (pochissimo rinforzando), tension accumulations followed by relaxation, sudden crossing from piano to subito fortissimo, or from mezzoforte to subito pianissimo, are procedures that colour discreetly this ambience music, inviting us to meditation. The choral music without words "is running on a vowel - slightly variable - located between $a$ and $o$ (more to $a$ ). It is recommended that the high passages and forte to be intonated on a more open vowel, and the passages on pianissimo to adopt a slightly darker colour. The vowel attack will be renewed at the same time as the beginning of a new legato, but not in a rough manner, but as shrouded as possible. Avoid portamenti as much as possible" [1, p. 1]. The composer's recommendations are particularly important, the subtlety of vowel colours being absolutely necessary in a high artistic interpretation. The effect of vocal expression without articulation of words is specific to the à cappella repertoire, or can be encountered in the opera genre, in moments when the choir accompanies vocalists. Highlighting this effect, by placing the choir to the fore, without vocal or instrumental contribution, is an ingenious novelty, which does not push on the forging of the spectacular, but on the contrary, proposes an opening to the most intimate saying, to the inner queries. The beauty of this choral page has led to its detachment and integration in the programme of choral concerts.

The courtiers enter the scene on the interlude (passacaglia) which precedes the third scene. Their physical presence is necessary throughout the 
whole duration of the mentioned scene. Their first intervention occurs at the moment when the King of the show predicts to the Queen that she will find another husband. The prophecy leads to the insertion of a choral line, which reminds us of the ancient choir, with glided chords on wordless humming, launched without bass support:

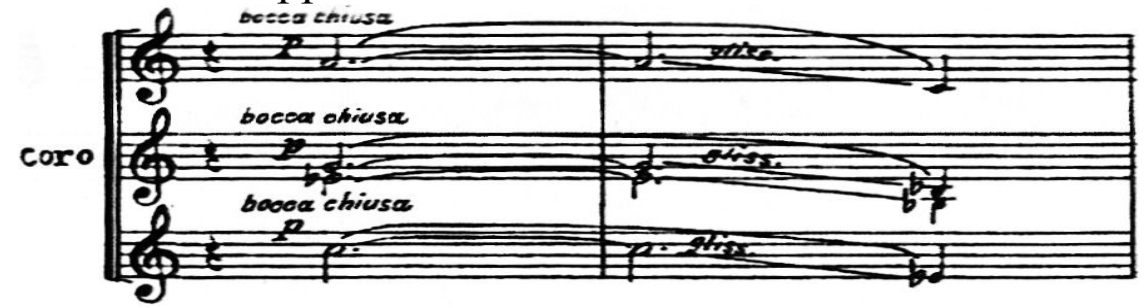

Figure no. 2. P. Bentoiu - Hamlet, 3rd scene, p. 47, mm. 539-540

Invoking the curse force, the Queen says that the woman who takes her second husband, kills her late husband once again, which means defaming the relationship. The courtiers' reaction does not require accurate intonation, because the exclamation "Ah" is a swiftly sliding sussurato in the downward direction. The female character strengthens her love vows, which raises the court's comments, both on great dynamics and piano. In the first case the female voices introduce a level of loudness through high, screaming sounds, which cause the same downward sliding. Each voice of the mixed choir is divided into two, and the imitating exposure"what a oath" borrows the glissando formula with a descending slope. The second case refers only to the group of female voices, because the piano dynamics is folding with mysterious sonority, soaked with suspense. In the formulation "strange happenings" the altos take the sopranos' plan to the octave, while the next one "it would end well with it" brings the unison with detachment in the form of a fan. The moment when the King of the play dies causes "a murmur of astonishment and consternation" [6, p. 130], and the mixed choir throws the exclamations in an ascending or a descending sense, or in waved enunciation (to alto). All voices are overlapping, are grouped two by two (women, men), the propelled cries covering all the choral space: from upper register - sopranos, to lower register - basses.

The first wider choral development is occasioned by the intervention of King Claudius, who rises suddenly and asks for light. The musical-dramatic wording goes out of the octave soprano-tenor, contralto-bass, and the empty fifths are filled with harmony. Major and minor chords, in root position or inverted, turn to the division in the choir's voices, agglomeration that guides to the augmentation of the dramatic propulsion. The keyword "light" appears no less than eight times, placed in the upper register of sopranos (touching H5), tenors (G4), or baritone-basses (E4). In homophone texture penetrate polyphonic techniques, the canon soprano-alto $\rightarrow$ tenor-bass preparing the descending chromatic sequence in ternary subdivision. With the last forces, the finalis of this passage is whispered and slided. There follows a conclusion section that suspends the articulation of the words, on an upward chromatic action of the 
voices, in soprano, alto, tenor, bass order, vocal contour in which the choir moves like "waves in a wheat field". So the participation of the choral ensemble in the third scene is progressively achieved, from short lines of the type of brief exclamations, to unfolded formulations. The dramatic action is supported by the courtiers, because the facts of the main characters are commented, or developed through the echo of the collective character.

The second act places the choir behind the scenes; we refer to the sixth scene, where the convoy of the Danish rebels, headed by Laertes, is in the vicinity of the castle. The idea of a parallel action appears, resulting a poliphony of the dramatic plans (conducted on stage and out of stage). The parallel fourths and fifths ring again between tenor-bass and soprano-alto, the sonorous packets appeal to homophonic texture, insinuated by imitative elements, the whole movement evolving from piano to forte. The enhancement of the dynamics overlaps with the idea of approaching ${ }^{28}$, and the forte dynamic marks the entrance of the choir into the scene. The heroic character of the moment is supported by the orchestral ensemble by ternary pulse, and the execution in detaché, highlighting accents is on the path on a viable performing. The triple formula goes from the orchestral to the choral plane, and the end of the episode it appeals to white sounds, placed in the high register:

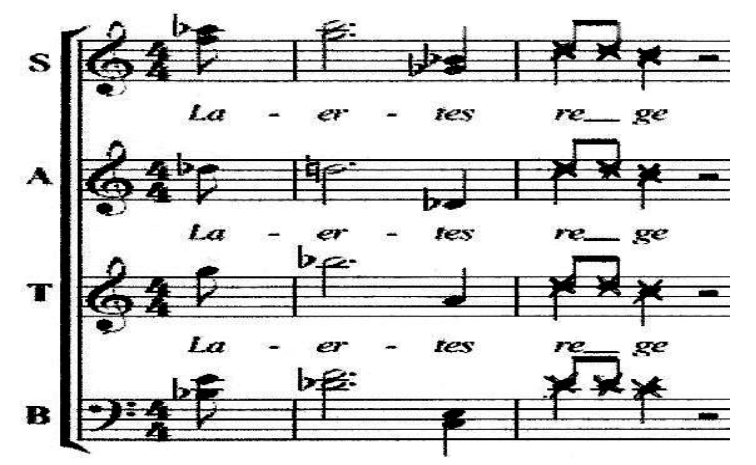

Figure no. 3. P. Bentoiu - Hamlet, 6th scene, p. 99-100, mm. 1028-1029

All voices slip between two strictly marked extremes; sussurato in fortissimo leaves the sphere of singing and proposes shouted sounds. The image of the death persists, which leads to the court's statement: he is dead! The vertical coordinate fills the fifth, this time, with minor chords, the terrible image being best outlined. Once obtained bi-tonal harmony, the choir supports the prolonged chord, then he diminishes from forte to pianissimo, on a dynamic retreat that enriches the choral expression, and, at the same time, gives way to the solo's later interventions. The end of the stage marks the return of Ophelia. The court supports the entrance of Laertes' sister, asking the guards to let her in. The musical phrase Let her in .. has a praying tone and not an imperative one, on

\footnotetext{
${ }^{128}$ A scenic effect commonly found in opera scores. We recall here the invisible choir (Eumenides) from Oedipus by G. Enescu, the choir behind the coulisse from the second act of The Plague by S. Drăgoi, or the priests' choir from the temple by the same act of Decebalus by Gh. Dumitrescu.
} 
a low dynamic. The starting treatment à cappella claimes the voices' shifted inputs, with initialis and finalis represented by soprano, respectively bass, while the middle brings the mixture of internal voices.

Choral extents also appear in the seventh scene, to accompany Ofelia's solo plan who retires, while King Claudius retains Laertes, to set up a plot. The soloist approach is in the limelight, so the choral ensemble carries on in the alternative a vocalization, outlining the world of Ofelia's alienation. The singsong with jelly resonances replaces the words with the vowels $o, a, u$, and the end of the musical articulation is projected into bocca chiusa. Like an echo of the world described, the female voices bring the movement of the eighth, the sonority diminishing even more - the minimal extreme is reached: pianississimo. The duel between Hamlet and Laertes is assisted by courtiers, and their interference guides choral formulations. The interjection $A h$ ! asks "glissando of female voices, engraving meanders on the vowel $a$, in unfolded packages, with oscillating senses" $[6, p$. 132]. The choir marks the moment when Hamlet stabs Laertes, through a rolling scream. When the Queen falls, the choral ensemble uses the soprano-contalto mixture, followed by tenors, with a sliding exclamation; the last breath of the Queen is found by the courtiers, who have no more power than to throw one $A h$ ! without timbre (senza timbro).

Running in Moderato, the end of the opera is attributed to the choir. So, the beginning and the end of the opera appeal to the collective character's commentary, the energy of choral deployments recalling the purifying effect of the tragedy (catharsis). Above a drone on $\mathrm{C}$, a madrigal rises on the deliverance a noble soul goes out. The sobriety of the moment appeals to a conjunct melodic motion intoned by the tenors, and submitted to imitation on an ascending path: tenor-alto-soprano+bass (the last exposure gets deeper). The second imitative episode keeps the low dynamics, and the musical sentence is built up by repeating the motif. The cumulation of the voices from the low to the high register suggests the rise of the soul, the aspiration of the human being to the high heavens. An à cappella passage appears, Good night, sweet Prince, where the superpositions of fourth and fifth are reiterated. The sonority gradually falls on the choral unison exposed by the soprano-alto-tenor triad (recitative singing). "The choral Lamento from the end creates a state of profound collectedness and dramatic nature, of grieved meditation on the previous events, on the meaning of the existence, life, and death" [6, p. 133].

Subtle and polychromatic orchestration appeals to a broad device, where the percussion part is equipped with no fewer than 20 instruments. The organ printed on the tape is added; records are overlapped with live executions. However, the orchestration is often very transparent, rarefied, reduced to a few instruments, and so the colouring is as expressive as possible. The choral ensemble in the Hamlet opera appears as a character taken out of the ancient tragedies, the choral lines taking the text of different characters, without having an own verbal contribution - an exception is the end of the opera. Finding or 
commenting demarches enliven the dramatic context and complete the musical deployment. Contemporaneousness of musical language, with moment of serial (Ofelia's madness) or aleatory treatment, weighting of innovation, with participation of electronics, "the rich world of Hamlet opera is revealed with force and austerity, intensity of emotion" [2, p.12].

\section{Conclusions}

Exploring the areas of tonal, atonal and modal language, Pascal Bentoiu has made his own way, knowing everything that happened in the music of the 20th century, and resisting to the many calls in a world of trends. The positioning of the creative self in the sphere of neo-romanticism is due to his lyrical attitude, poetry, by excellence, without neglecting the rigour of musical construction. The lyrical experiences have quickly unrolled, his three operas being conceived over just five years (1964-1969). Pascal Bentoiu did not dedicate himself to the choral music ${ }^{129}$, but the virtues of the choral sonorities were exploited in The Sacrifice of Iphigenia and Hamlet, through various plurivocal formulatios, which presented the music-word binomial in the form of monadic entity, whose presence was dictated by the logic of dramatic deployment. In his operas the traditional conventions have softened, without being removed, aiming at refining the poetic expression put into the service of sound art.

\section{References}

1. Bentoiu, P. (1972). Hamlet, canto-piano score. Milano: Edizioni Suvini Zerboni.

2. Constantinescu, G. (1974). Hamlet by Pascal Bentoiu, in Journal Muzica, nr. 3/1974. Bucharest: Musical Publishing House.

3. Constantinescu, G. (1979). Cântecul lui Orfeu. Bucharest: Eminescu Publishing House.

4. Constantinescu, G. (2008). Splendorile operei. Dicționar de teatru liric. Bucharest: Didactic and Pedagogical Publishing House.

5. Cosma, M. (2001). Opera în România privită în context european. Bucharest: Musical Publishing House.

6. Cosma, O. L. (1981). Dramaturgia operei contemporane româneşti Hamlet de Pascal Bentoiu in Studii de muzicologie, vol. XVI. Bucharest: Musical Publishing House.

7. Popovici, D. (1970). Muzica românească contemporană. Bucharest: Albatros Publishing House.

\footnotetext{
${ }^{129}$ We remember the religious work, I praise You, Father, composed in 1981, and dedicated to his friend Vasile Spătărelu.
} 